\title{
Immunotoxin CMD-193
}

National Cancer Institute

\section{Source}

National Cancer Institute. Immunotoxin CMD-193. NCI Thesaurus. Code C62480.

A humanized immunotoxin directed ag ainst the Lewis $Y$ antigen conjug ated with

calicheamicin, a hydrophobic enediyne antibiotic, with potential antineoplastic activity.

CMD193 binds to the Lewis $Y$ antigen, a tetrasaccharide expressed on the cell surfaces of many tumor cell types. Upon binding, CMD-193 is internalized, thereby delivering the attached calicheamicin to Lewis Y antigen-expressing tumor cells. Calicheamicin binds non-covalently to the minor groove of DNA and prompts conformational changes and DNA oxidation, thereby inhibiting DNA synthesis and inducing apoptosis. 